\title{
The use of a raindrop aggregate destruction device to evaluate sediment and soil organic carbon transport
}

\author{
L. Xiao, Y. Hu, P. Greenwood, and N. J. Kuhn \\ Physical Geography and Environmental Change Group, Department of Environmental Sciences, University of \\ Basel, Klingelbergstrasse 27, 4056 Basel, Switzerland \\ Correspondence to: L. Xiao (liangang.xiao@unibas.ch)
}

Received: 29 September 2014 - Revised: 27 May 2015 - Accepted: 31 May 2015 - Published: 15 June 2015

\begin{abstract}
Raindrop impact and subsequent aggregate breakdown can potentially change the movement behaviour of soil fractions and thus alter their transport distances when compared against non-impacted aggregates. In a given water layer, the transport distances of eroded soil fractions, and thus that of the associated substances across landscapes, such as soil organic carbon (SOC) and phosphorous, are determined by the settling velocities of the eroded soil fractions. However, using mineral size distribution to represent the settling velocities of soil fractions, as often applied in current erosion models, would ignore the potential influence of aggregation on the settling behaviour of soil fractions. The destructive effects of raindrops impacting onto aggregates are also often neglected in current soil erosion models. Therefore, the objective of this study is to develop a proxy method to effectively simulate aggregate breakdown under raindrop impact, and further identify the settling velocity of eroded sediment and the associated SOC.

Two agricultural soils with different sandy and silty loam textures were subjected to rainfall using a raindrop aggregate destruction device (RADD). The aggregates sustained after raindrop impact were fractionated by a settling tube into six different classes according to their respective settling velocities. The same mass amount of bulk soil of each soil type was also dispersed and sieved into the same six classes, to form a comparison in size distribution. The SOC content was measured for each settled and dispersed class. Our results show the following: (1) for an aggregated soil, applying dispersed mineral grain size distribution, rather than its actual aggregate distribution, to soil erosion models would lead to a biased estimation on the redistribution of eroded sediment and SOC; (2) the RADD designed in this study effectively captures the effects of raindrop impact on aggregate destruction and is thus able to simulate the quasi-natural sediment spatial redistribution; (3) further RADD tests with more soils under standard rainfall combined with local rainfalls are required to optimize the method.
\end{abstract}

1

\section{Introduction}

Erosion is generally considered as a three-step process that includes detachment, transport, and deposition (Lal, 2005; van Oost et al., 2007). After being detached (Le Bissonnais, 1996; Legout et al., 2005), soil particles may experience selective deposition across landscapes, or be further transported to aquatic systems (Stallard, 1998; Starr et al., 2000; Lal, 2005; Kuhn et al., 2009). Hence, the destruction of soil aggregates during detachment, transport, and deposition can potentially affect the transport distance of eroded soil fractions. Discrimination of eroded soil fractions accord- ing to their likely transport distances, therefore, is essential to fully understand the movement of eroded sediment (van Oost et al., 2004), and thus the redistribution patterns of sediment-bound substances such as organic carbon and phosphorous across landscapes (Quinton et al., 2001; Lal, 2004; van Oost et al., 2007; Kuhn and Armstrong, 2012; Hu and Kuhn, 2014).

Apart from flow velocity, depth, and turbulence, the transport distance of a certain particle is closely related to its settling velocity (Kinnell, 2001, 2005; Kuhn, 2013). Settling velocity converted from mineral grain size distribution (e.g. Stokes, 1851; Gibbs et al., 1971; Hallermeier, 1981; Diet- 
Table 1. Particle parameters adopted in currently used erosion models.

\begin{tabular}{lllll}
\hline Studies & Name or purpose of model & Particle type & Classes & Particle range \\
\hline van Oost et al. (2004) & MCST & grain & 10 & $0.9-91.35 \mu \mathrm{m}$ \\
Lu et al. (2006) & Modelling sediment delivery & grain & 3 & Clay $(<4 \mu \mathrm{m})$, silt $(4-50 \mu \mathrm{m})$, sand $(50-1000 \mu \mathrm{m})$ \\
Pieri et al. (2007) & WEPP & grain & 3 & Coarse sand, fine sand, clay \\
De Baets et al. (2008) & EUROSEM & grain & 1 & $42 \mu \mathrm{m}$ (median size) \\
\hline
\end{tabular}

rich, 1982; Cheng, 1997; Ferguson and Church, 2004) has been applied to erosion models (Table 1). However, soil is not always eroded as individual mineral grains, but it is mostly eroded in the form of aggregates (Walling, 1988; Nadeu et al., 2011). The settling velocities of aggregated soil fractions are different from those of individual mineral grains. For instance, aggregation could considerably increase the sizes of soil fractions by combining mineral grains into aggregates, and thus facilitate their settling velocities. In addition, the upper limits of mineral grain size classes used in current erosion models are often smaller than the actual aggregate sizes. For example, the largest mineral grain size class used in the model by van Oost et al. (2004) is only $90 \mu \mathrm{m}$ (Table 1), which is much smaller than the largest naturally eroded aggregates (e.g. $>500 \mu \mathrm{m}$ reported by Hu and Kuhn, 2014). Furthermore, the settling velocity of a mineral grain and aggregate of the same size are also different due to differences in their respective shape and density (Dietrich, 1982; Loch, 2001). Therefore, using the actual settling velocities of eroded aggregates, rather than that converted from dispersed mineral grain size distribution, could contribute to providing more accurate input into erosion models.

Field investigations and simulated rainfall experiments under laboratory conditions are the two common methods for collecting natural or quasi-natural eroded aggregates (Croft et al., 2012a). For example, Hu and Kuhn (2014) used a $150 \times 80 \mathrm{~cm}$ flume under simulated rainfall to generate quasinatural sediment to predict the transport fate of sediment and soil organic carbon (SOC) eroded from a silty loam (Fig. 1a). However, these methods are often too time consuming and resource demanding to be of practical use. Hence, as an alternative solution, data on aggregate size distribution, based on wet-sieving, have occasionally been used in erosion models to represent settling velocity distribution of soil fractions (e.g. Angima et al., 2003). However, calculating settling velocity solely based on aggregate size ignores the potential influence of porosity, irregular shape, and the involvement of organic matter on the settling behaviour of wet aggregates. In addition, wet-sieving does not account for the potential effects of raindrop impact on aggregate breakdown (e.g. mechanical breakdown, slaking, dispersion, and liquefaction, Le Bissonnais, 1996) and, thus, possible changes on settling velocities of soil fractions. Therefore, it is crucial to develop a simple but efficient proxy method to effectively capture the potential influence of raindrop-impact-induced aggregate
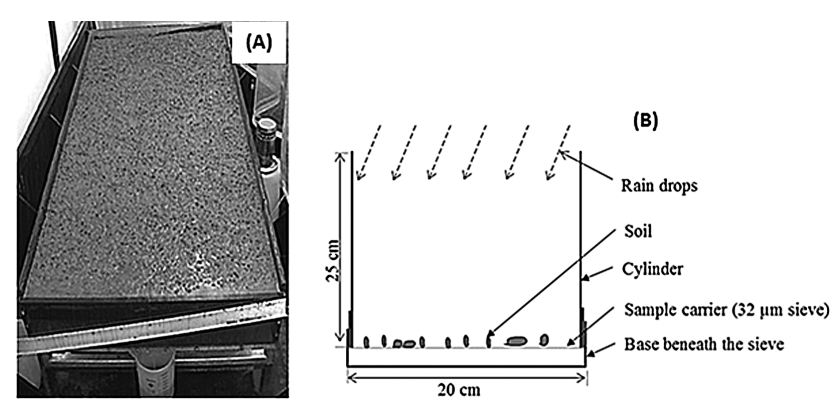

Figure 1. The flume used by Hu and Kuhn (2014) (a) and the raindrop aggregate destruction device (RADD) used in this study (b).

breakdown on the transport distance of sediment and eroded SOC.

This study aims to develop a raindrop aggregate destruction device (RADD) for use as a sensitive proxy, to effectively simulate aggregate breakdown under raindrop impact, and further identify the settling velocity of eroded sediment and the associated SOC. Two soils with contrasting textures - one a poorly aggregated sandy soil and the other a wellaggregated silty loam - were first broken down using the RADD to generate raindrop-impacted soil particles, which were then fractionated using a settling tube apparatus. The influence of aggregation on settling velocity distribution was then highlighted by comparing the settling velocity distributions of the aggregates and/or grains of the two soils, as well against their mineral grain size distributions. The effectiveness of this RADD proxy method was then assessed by comparing the settling velocity distribution of the aggregated silty loam generated from the RADD with that of the same silty loam from a flume experiment conducted by $\mathrm{Hu}$ and Kuhn (2014).

\section{Materials and methods}

\subsection{Soil samples and preparations}

Two soils - one a sandy soil from Denmark and one a silty loam from Switzerland - were used in this investigation. The sandy soil from Denmark, characterized as a Luvisol (FAO/ISRIC/ISSS, 1998), was collected in September 2011 from a conventionally managed farm under a rotation of wheat and maize in Foulum $\left(56^{\circ} 30^{\prime} \mathrm{N}, 9^{\circ} 35^{\prime} \mathrm{W}\right)$, central Jutland, in northern Denmark. The silt loam from Switzerland, 
Table 2. Texture, SOC content and stable aggregates greater than $250 \mu \mathrm{m}(\%)$ of the Foulum and Möhlin bulk soils. Numbers in brackets represent standard deviations.

\begin{tabular}{llllll}
\hline Soils & Sand $(\%)$ & Silt $(\%)$ & Clay $(\%)$ & SOC $\left(\mathrm{mg} \mathrm{g}^{-1}\right)$ & $\begin{array}{l}\text { Stable aggregates } \\
>250 \mu \mathrm{m}(\%)\end{array}$ \\
\hline Möhlin & $16.14(0.34)$ & $77.00(0.36)$ & $6.85(0.04)$ & $9.60(0.10)$ & $66.85(0.47)$ \\
Foulum & $77.19(0.40)$ & $21.00(0.38)$ & $1.81(0.02)$ & $11.00(0.30)$ & No stable aggregate \\
\hline
\end{tabular}

recognized as a Luvisol (FAO/ISRIC/ISSS, 1998), was collected in March 2012 from a conventionally managed farm supporting a rotation of wheat, rape, grass and maize located in the Möhlin region $\left(47^{\circ} 33^{\prime} \mathrm{N}, 7^{\circ} 50 \mathrm{~W}\right)$ of north Switzerland. The selective properties of the two soils are summarized in Table 2. Although the sampling time of each soil was different, the two soils were ploughed before sampling, which provided similar field surface conditions. In addition, both sampling sites are prone to erosion due to intensive agriculture (Olsen and Kristensen, 1998; Croft et al., 2012b). Due to contrasting aggregation conditions, the two soils were expected to generate different size distributions after direct raindrop impact, which very likely leads to different movement patterns and thus different redistribution patterns of SOC across the landscape.

After sampling, the two soils were air-dried at a temperature of $20^{\circ} \mathrm{C}$ for ca. 2 weeks until $10 \%$ water content was reached. Such air-dried aggregates can resemble soil surface conditions and have been widely used in raindrop splash experiments (Legout et al., 2005). The well-aggregated Möhlin soil was then dry-sieved through an $8 \mathrm{~mm}$ mesh, to exclude over-sized aggregates which may excessively resist raindrop impact and thus skew the proportion of coarse aggregates that survive raindrop impact. Whilst this process may, in retrospect, skew the aggregate distribution of the Möhlin soil towards finer size, this result in an over-representation of fine particles, most of which may remain in suspension in overland flow when transport processes occur. However, the standard-sized clods can ensure a comparable reaction to accumulating raindrop impact. As the Foulum soil was very poorly aggregated with no aggregates exceeding $8 \mathrm{~mm}$, it was considered to be standard-sized and thus was not drysieved. It should be noted that the pre-treatment is flexible. Where other aggregate moisture or seasonality conditions are applied, pre-treatment protocols should be accordingly adjusted.

\subsection{Raindrop aggregate destruction device and rainfall simulation}

A raindrop aggregate destruction device (RADD) (Fig. 1b) was designed to simulate the physical process when aggregates are subject to direct raindrop impact. To fulfil this, the RADD must meet two requirements: firstly, it must ensure that sufficient raindrops impact on the aggregate surfaces without being attenuated by surface flow; secondly, a certain degree of water ponding is necessary to mimic natural soil surface conditions that are essential to initiate overland flow during an erosion event. Based on the above premises, the RADD developed in this study consists of three parts. The first is a sample carrier - a $32 \mu \mathrm{m}$ diameter sieve to hold the dry soil samples prior to raindrop impact, as well to collect aggregates/particles surviving raindrop impact. In addition, the sieve also allows free drainage, which prevents over accumulation of surface water, but ensures that a certain degree of ponding occurs. The second is a base beneath the sample carrier to collect fine particles and redundant water passing through the sieve. The third is a $25 \mathrm{~cm}$ tall cylinder embracing the sample carrier, which is $20 \mathrm{~cm}$ higher than the surface of the carrier and is designed to prevent the removal and loss of splashed particles (Fig. 1b).

A total of $25 \mathrm{~g}$ (dry weight) of each soil was distributed uniformly on the sample carrier of the RADD to fully cover the sieve, and then subjected to simulated rainfall (Fig. 1b). This configuration ensured maximum exposure of the aggregates to the impacting raindrops, as well as generating sufficient materials in order to perform settling fractionation tests. During rainfall experiments, the depth of ponding water in the sample carrier was ca. 1-2 mm (operator's on-site observation), which is representative of overland flow during the flume test conducted by $\mathrm{Hu}$ and Kuhn (2014). Given that these estimates were so small, the proportion of material lost to raindrop splash erosion was not accounted for in this study.

Simulated rainfall was generated using a Lechler full cone nozzle (type +460.728.30.CE), with a fall height of $2 \mathrm{~m}$ over the RADD, with an average intensity of $35 \mathrm{~mm} \mathrm{~h}^{-1}$. Average drop size was ca. $2.2 \mathrm{~mm}$, with a kinetic energy of $105 \mathrm{~J} \mathrm{~m}^{-2} \mathrm{~h}^{-1}$, measured using a Joss-Waldvogel disdrometer. Because the Möhlin soil is more aggregated and the size distribution is thus more sensitive to raindrop impact than the Foulum soil, simulated rainfall scenarios were chosen to more resemble precipitation conditions in the Möhlin region. Precipitation with an intensity of $35 \mathrm{~mm} \mathrm{~h}^{-1}$ is very common in the Möhlin region, and has a return period of 0.33 years (MeteoSwiss, 2013). Previous research has shown that ensuring complete aggregate breakdown requires a kinetic energy of $150 \mathrm{~J} \mathrm{~m}^{-2}$ (Hu and Kuhn, 2014). Such kinetic energy corresponds to natural precipitation at the above intensity for $15 \mathrm{~min}$ (Iserloh et al., 2012). Given that the kinetic energy of simulated rainfall is typically lower than that during natural 
precipitation (Iserloh et al., 2012; Hu and Kuhn, 2014), increasing the intensity or prolonging the duration of an event is commonly used as a compensatory approach to generate conditions that are more comparable to natural precipitation. In addition, rainfall kinetic energy is a more relevant variable than cumulative rainfall when investigating soil surface dynamics (Torri et al., 1999). Therefore, simulated rainfall of $35 \mathrm{~mm} \mathrm{~h}^{-1}$ lasting for $90 \mathrm{~min}$ with a cumulative kinetic energy about $150 \mathrm{~J} \mathrm{~m}^{-2}$ was chosen in this study to sufficiently break down aggregates. Furthermore, in order to observe the sensitivity of aggregation to increasing kinetic energy, rainfall events with increasing durations of $15,30,45,60$, and 90 min were separately applied (not in a sequence) to the two soils in order to simulate the cumulative kinetic energy of 26, $52,78,104$, and $156 \mathrm{~J} \mathrm{~m}^{-2}$, respectively. During each rainfall event, three replications were conducted simultaneously for each soil.

Tap water with an electric conductivity of $2220 \mu \mathrm{sm}^{-1}$, which was 5 times greater than local rainwater $\left(462 \mu \mathrm{cm}^{-1}\right)$, was used for each test. Although higher electric conductivity of tap water may increase the dispersion of aggregates (e.g. Borselli et al., 2001), a preliminary study has shown its influence on aggregate breakdown of the two soils used in this study is negligible (Hu et al., 2013a).

\subsection{Settling tube and settling velocity measurement}

The settling tube used in this study is similar to the Griffith tube (Hairsine and McTainsh, 1986; Loch, 2001; Hu et al., 2013b) and consists of four major components: a settling tube, an injection device, a turntable, and a control panel (Fig. 2). Detailed information about the setup and operation of the settling tube has been described in $\mathrm{Hu}$ et al. (2013b). After destroyed by the increasing raindrop impact in the RADD, all soil fractions remaining on the carrier sieve were washed into the injector to conduct fractionation tests (Fig. 2). Given that the settling velocity distribution of aggregates is different from that of mineral grains, and cannot be directly converted from aggregate diameter, we used the concept of equivalent quartz size (EQS) to represent the diameter of a spherical quartz particle that would deposit with the same velocity as an aggregated particle (Loch, 2001; Hu et al., 2013b; Hu and Kuhn, 2014). Based on Stokes' law and the concept of EQS, six settling classes were chosen in this study to fractionate the raindrop-impacted soil fractions: 500 to $1000 \mu \mathrm{m}, 250$ to $500 \mu \mathrm{m}, 125$ to $250 \mu \mathrm{m}, 62$ to $125 \mu \mathrm{m}$, 32 to $62 \mu \mathrm{m}$, and $<32 \mu \mathrm{m}$ (Table 3). The finest particles remaining suspended in the settling tube (of EQS $<32 \mu \mathrm{m}$ ), plus those collected in the base beneath the $32 \mu \mathrm{m}$ sample carrier sieve during the raindrop impact simulation (Table 3), were pooled together and treated as one subsample (EQS $<32 \mu \mathrm{m}$ ).

Following the conceptual model proposed by Starr et al. (2000), which predicts that the fate of eroded SOC is a function of particle size, it is assumed in this study that

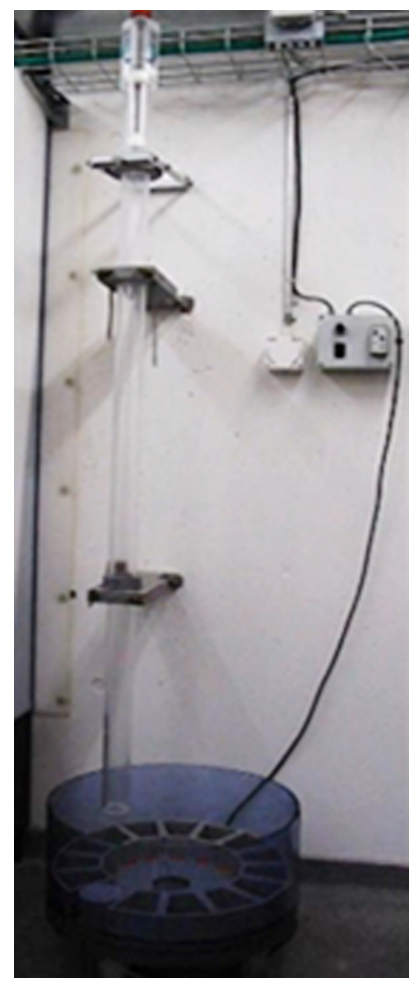

Figure 2. Settling tube apparatus used in this study. Detailed technical and operation information has been reported in $\mathrm{Hu}$ et al. (2013).

fractions of EQS $>62 \mu \mathrm{m}$ would be potentially re-deposited across landscapes. In contrast, fine particles of EQS $<62 \mu \mathrm{m}$ would be transported furthest from their point of origin and thus have the potential to enter aquatic systems (Table 3). There may be some discrepancies induced by the "primary silt-sized particles" measured in Starr et al. (2000) and the concept of EQS used in this study. Yet, for a certain particle, its EQS is either smaller than (as an aggregate) or equivalent to (as a mineral grain) its actual diameter (as measured in Starr et al., 2000). Therefore, it should be noted that taking $62 \mu \mathrm{m}$ EQS measurement as a cut-off point by which the potential fate of eroded soil fractions may be determined could result in slightly underestimating re-deposition across landscapes.

\subsection{Mineral grain size distribution}

In order to compare the different size distributions of EQS fractions and that of mineral grains, $25 \mathrm{~g}$ of bulk soil from each soil type was dispersed using a Sonifier 250 (Branson, USA). The energy dissipated in the water-soil suspension was ca. $60 \mathrm{~J} \mathrm{~mL}^{-1}$, which accords with the approach adopted by Kaiser et al. (2012). To correspond to the six EQS fractions fractionated by the settling tube, the dispersed soil fractions were then wet-sieved into six size classes listed above. Three replications were conducted for each soil. 
Table 3. Settling time intervals, settling velocity, equivalent quartz size (EQS), class and possible fate of each fraction.

\begin{tabular}{lrrll}
\hline Time intervals $(\mathrm{s})$ & Settling velocity $\left(\mathrm{m} \mathrm{s}^{-1}\right)$ & EQS $(\mu \mathrm{m})$ & Class & Possible fate \\
\hline Before 20 & $>0.09$ & $>500$ & & \\
$20-40$ & $0.045-0.09$ & $250-500$ & Fast-settling & Deposit on landscape \\
$40-120$ & $0.015-0.045$ & $125-250$ & & \\
$120-600$ & $0.003-0.015$ & $62-125$ & Medium-settling & \\
$600-1800$ & $0.001-0.003$ & $32-62$ & Slow-settling & Transport to river \\
After 1800 & $<0.001$ & $<32$ & & \\
\hline
\end{tabular}

\subsection{Laboratory measurements}

After the fractionation and ultrasonic dispersion, all the EQS and dispersed soil fractions were dried at $40^{\circ} \mathrm{C}$ and weighed. The SOC concentration of each EQS and dispersed soil fraction was determined using a Leco 612 carbon analyzer following the method of $\mathrm{Hu}$ et al. (2013a). The SOC was burnt at $550^{\circ} \mathrm{C}$ for $200 \mathrm{~s}$ and all carbon fractions were detected as $\mathrm{CO}_{2}$. The SOC mass distribution across EQS and dispersed classes was calculated by multiplying the SOC concentration of each class with their individual weight proportions. Data analysis was carried out using Microsoft Excel 2010 and SPSS 16.0 software packages.

\section{Results and discussion}

\subsection{Aggregation effects}

The EQS distributions of the Möhlin and Foulum soils after raindrop impact using the RADD are shown in Fig. 3 and compared with the corresponding mineral grain size distribution. The EQS distributions differed profoundly between the aggregated Möhlin soil and the sandy Foulum soil (Fig. 3a, b). For the Möhlin soil, 45 to $73 \%$ of the aggregated fractions were of EQS $>62 \mu \mathrm{m}$. This strongly contrasts the Möhlin mineral grain size distribution, which suggests that only $10 \%$ of the mineral grains were of size $>62 \mu \mathrm{m}$ (Fig. 3a). Consequently, up to $77 \%$ of the total SOC was associated with the soil fractions of EQS $>62 \mu \mathrm{m}$ (Figs. $4 \mathrm{a}$ and 5a), which would be re-deposited across landscapes following the $62 \mu \mathrm{m}$ cutoff proposed by Starr et al. (2000) (Table 3). It strongly contrasts the $10 \%$ SOC contained in the mineral grains of size $>62 \mu \mathrm{m}$ (Figs. 4a, 5a). If estimated by mineral-grain-specific SOC distribution, this would underestimate the re-deposition of aggregated SOC across landscapes by up to $67 \%$. Such discrepancies highlight that the effects of aggregation can potentially facilitate the settling velocity and thus reduce the likely transport distances of aggregated sediment and the associated SOC, hence skewing their deposition towards the terrestrial systems. For the sandy Foulum soil, the EQS distribution was well matched with the mineral grain size distribution, illustrating the absence of aggregation effects to alter soil size distribution (Fig. 3b). This consequently resulted in a roughly consistent SOC distribution across EQS and min-

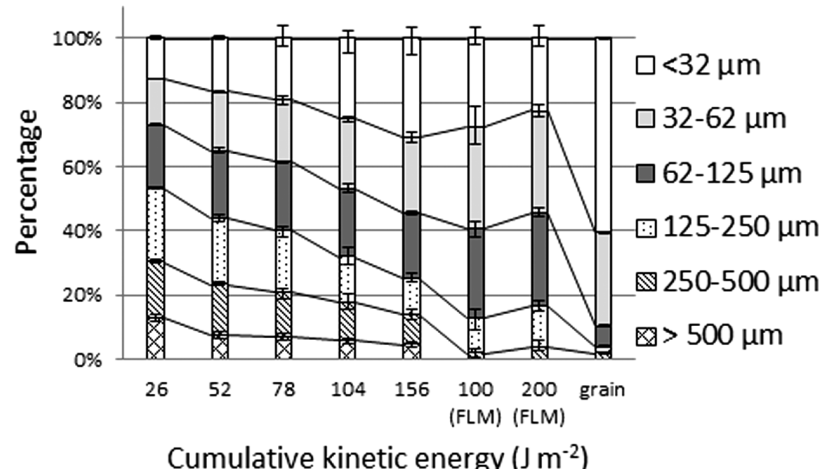

(B)

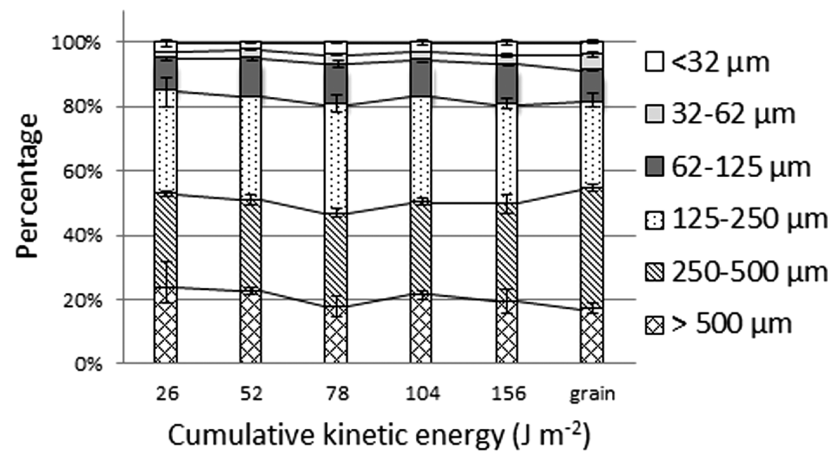

Figure 3. The equivalent quartz size (EQS) distributions of (a) the Möhlin soil and (b) the Foulum soil after different cumulative kinetic energy. The columns "100 (FLM)" and "200 (FLM)" represent the EQS distribution of eroded sediment from a flume (FLM) (Hu and Kuhn, 2014) after 100 and $200 \mathrm{~J} \mathrm{~m}^{-2}$ of cumulative kinetic energy impact. "Grain" represents the grain size distribution by wetsieving after ultrasonic dispersion. Upper and lower bars represent maximum and minimum values, respectively.

eral grain classes (Figs. 4b, 5b). No significant difference was detected for each class $(P>0.05)$ (Fig. 4b). 

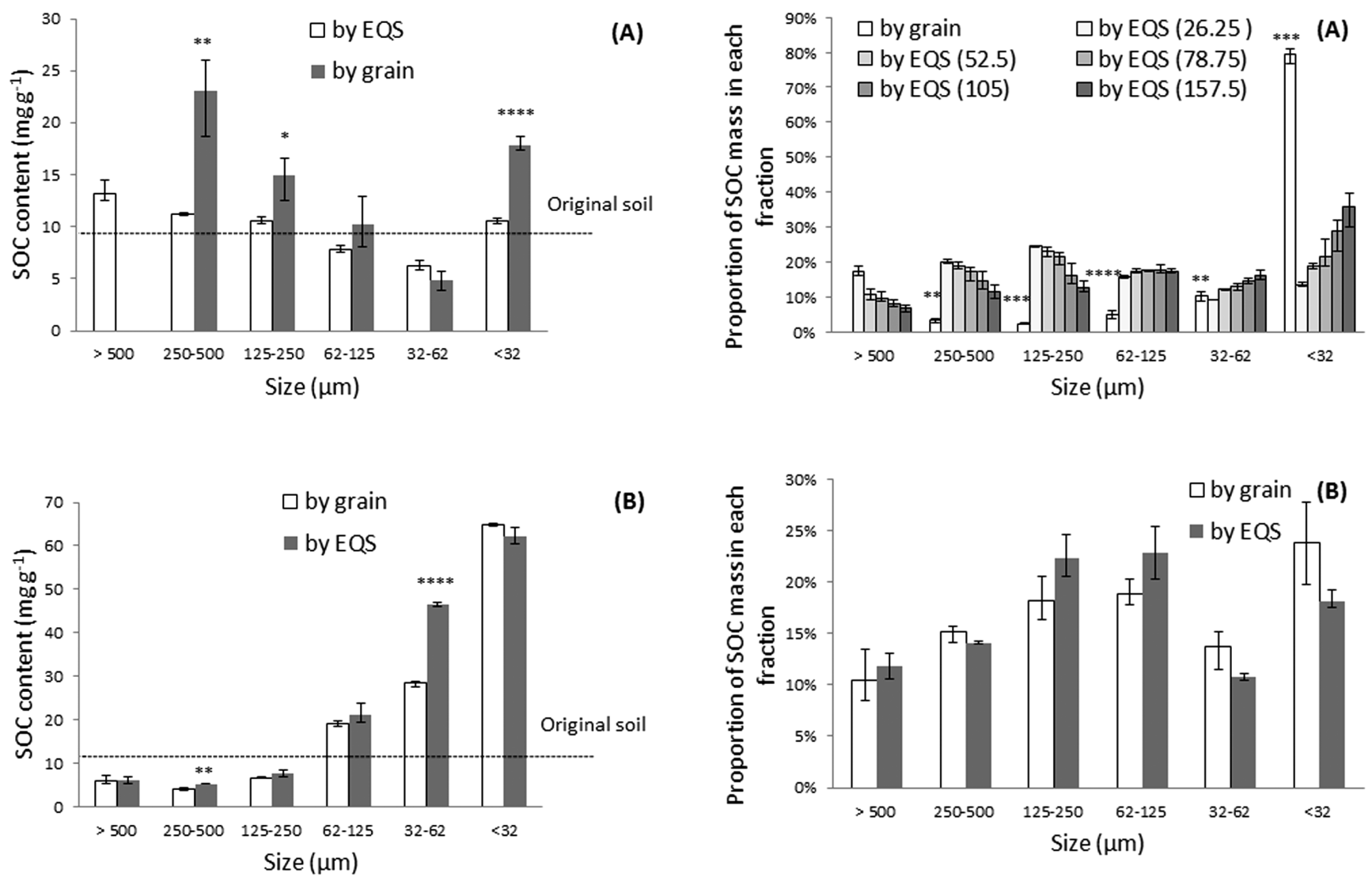

Figure 4. Soil organic carbon (SOC) content across equivalent quartz size (EQS) fractions fractionated by the settling and across grain size classes dispersed by ultrasound of (a) the Möhlin soil and (b) the Foulum soil. The "*” indicates significant difference at $P<0.05$ level, the “***" indicates significant difference at $P<0.01$ level, and the “****” indicates significant difference at $P<0.0001$ level between SOC content of each fraction by EQS and by grain. Upper and lower bars represent maximum and minimum values, respectively.

\subsection{Sensitivity to accumulative kinetic energy}

The sensitivity of EQS size distribution to increasing kinetic energy also differed between the Möhlin and Foulum soils (Fig. 3). For the Möhlin soil, fractions of EQS $<62 \mu \mathrm{m}$ increased significantly as the kinetic energy accumulated from 26 to $156 \mathrm{~J} \mathrm{~m}^{-2}(P<0.01)$ (Fig. 3a), but the increased kinetic energy had only minor influences on the EQS distribution of the Foulum soil (Fig. 3b). The significant changes in EQS distribution are probably due to the destruction of the Möhlin aggregates of EQS $>125 \mu \mathrm{m}$ upon raindrop impact. This may induce the gradual release of more fine particles as kinetic energy increases (Legout et al., 2005). However, for the Foulum soil, because of the sandy characteristics and thus lack of aggregation effects (Table 2), soil fractions did not act in response to the higher kinetic energy associated with impacting raindrops. The different soil responses between

Figure 5. The soil organic carbon (SOC) mass of different fractions of (a) the Möhlin soil and (b) the Foulum soil. The numbers in the brackets are the cumulative kinetic energy of each rainfall $\left(\mathrm{J} \mathrm{m}^{-2}\right)$. The "**" indicates significant difference at $P<0.01$ level, the "***" indicates significant difference at $P<0.001$ level, and the "****" indicates significant difference at $P<0.0001$ level between SOC mass proportion by grain and by equivalent quartz size (EQS). Upper and lower bars represent maximum and minimum values, respectively.

the Möhlin and the Foulum soil against raindrop impact suggest that a simple texture measurement is sufficient to predict the likely transport distances of soil fractions for poorly aggregated soils. However, investigating the natural breakdown processes of well-aggregated soils requires a proxy, such as the RADD developed in this study, to efficiently simulate quasi-natural sediment.

\subsection{Effectiveness of the RADD}

The effectiveness of the RADD, as a proxy method for generating quasi-natural sediment, can also be verified by the comparable EQS distributions for the same Möhlin soil (Fig. 3a) collected from the RADD in this study (when receiving kinetic energy of $156 \mathrm{~J} \mathrm{~m}^{-2}$ ) and that from the previous flume experiment (Hu and Kuhn, 2014). For all the settling classes, except that of EQS $>250 \mu \mathrm{m}$, the proportional EQS distributions are quite similar between RADD-destroyed aggregates in this study and the sediment generated from the flume and 
reported by $\mathrm{Hu}$ and Kuhn (2014). The lack of fractions of EQS $>250 \mu \mathrm{m}$ in the flume experiment reported by $\mathrm{Hu}$ and Kuhn (2014) is mainly because not all the dispersed aggregates were transported out of the flume. Instead, some aggregates $>250 \mu \mathrm{m}$ were deposited across the surface. Therefore, our results suggest that the simple RADD is an effective proxy to simulate aggregate breakdown upon direct raindrop impact and generate quasi-natural sediment in a simple and more time-efficient way. It also demonstrates the possibility of contributing to generating a more representative input to erosion models. For example, in the Multi-Class Sediment Transport model (MCST) (van Oost et al., 2004), instead of inputting the settling velocity classes calculated from mineral grain size distributions, it is possible to directly apply the actual aggregate settling information identified by RADD to predict soil erosion risk. Moreover, if further applying such effective proxy to SOC distribution, the RADD also promises the potential to develop a SOC erodibility index with a reasonable resemblance to natural SOC erosion processes. While our results are limited by the preliminary experiments having been conducted on only two soil types, other factors such as seasonality (Le Bissonnais, 1996) and transport process under various water flow conditions (Wang et al., 2014) were also not accounted for; the RADD provides a proxy method to effectively separate the complex erosion process into individual processes. This therefore offers an opportunity to identify the potential effects of aggregation and raindrop impact on the spatial distribution of sediment and eroded SOC in a more efficient manner when compared to the traditional approach, based on mineral-grain-specific SOC distribution.

\section{Conclusions}

This study aimed to develop a simple method using raindrop aggregate destruction device (RADD) as a proxy to generate quasi-natural sediment, and to further identify the effects of aggregation on the settling velocity of sediment and the associated SOC. The settling distributions of an aggregated loamy soil and a poorly aggregated sandy soil were different from each other. In particular, the settling-specific SOC distribution for the aggregated loamy soil strongly contrasted its mineral-grain-size-specific SOC distribution. The aggregated SOC potentially re-deposited within terrestrial systems was up to $67 \%$ more than that estimated by mineral-grainsize-specific SOC distribution. This clearly demonstrates the risk of underestimating SOC redistribution within terrestrial systems if ignoring the effect of aggregation or neglecting the dynamics of aggregate breakdown upon raindrop impact. This highlights the necessity for an effective proxy such as the RADD developed in this study as a means of generating quasi-natural sediment for well-aggregated soil. While our results from the RADD are only based on two soils, it demonstrates a possibility to contribute to generating a more repre- sentative input to erosion models. However, in the future, a wider range of soils with various aggregation characteristics should be investigated under more varied rainfall conditions in order to support the results observed in this study, and to thus help optimize the RADD apparatus during further research.

Acknowledgements. We are grateful to the support of China scholarship council (CSC) and University of Basel. The contribution of Ruth Strunk is also acknowledged. Particularly, we want to thank Marianne Caroni, who passed away but is still sorely missed in our group.

Edited by: M. Hoelzle

Reviewed by: three anonymous referees

\section{References}

Angima, S. D., Stott, D. E., O’Neill, M. K., Ong, C. K., and Weesies, G. A.: Soil erosion prediction using RUSLE for central Kenyan highland conditions, Agric. Ecosyst. Environ., 97, 295-308, 2003.

Borselli, L., Torri, D., Poesen, J., and Sanchis, P.: Effects of water quality on infiltration, runoff and interrill erosion processes during simulated rainfall, Earth Surf. Process. Landf., 26, 329-342, 2001.

Cheng, N. S.: Simplified settling velocity formula for sediment particle, J. Hydraul. Res., 123, 149-152, 1997.

Croft, H., Kuhn, N. J., and Anderson, K.: On the use of remote sensing techniques for monitoring spatio-temporal soil organic carbon dynamics in agricultural systems, Catena, 94, 64-74, 2012a.

Croft, H., Anderson, K., and Kuhn, N. J.: Reflectance anisotropy for measuring soil surface roughness of multiple soil types, Catena, 93, 87-96, 2012b.

De Baets, D., Torri, D., Poesen, J., and Meersmans, J.: Modelling increased soil cohesion due to roots with EUROSEM, Earth Surf. Process. Land., 33, 1948-1963, 2008.

Dietrich, W. E.: Settling velocity of natural particles, Water Resour Res., 18, 1615-1626, 1982.

FAO/ISRIC/ISSS: World Reference Base for Soil Resources, FAO Rome, 1998.

Ferguson, R. I. and Church, M.: A simple universal equation for grain settling velocity, J. Sediment Res., 74, 933-937, 2004.

Gibbs, R. J., Matthews, M. D., and Link, D. A.: The relationship between sphere size and settling velocity, J. Sediment Petrol., 41, 7-18, 1971.

Hairsine, P. B. and McTainsh, G. H.: The Griffith tube: a simple settling tube for the measurement of settling velocity of soil aggregates, AES working paper 3/86, Griffith University, Brisbane, 1986.

Hallermeier, R. J.: Terminal settling velocity of commonly occurring sand grains, Sedimentology, 28, 859-865, 1981.

$\mathrm{Hu}$, Y. and Kuhn, N. J.: Aggregates reduce transport distance of soil organic carbon: are our balances correct?, Biogeosciences, 11, 6209-6219, doi:10.5194/bg-11-6209-2014, 2014.

$\mathrm{Hu}$, Y., Fister, W., and Kuhn, N. J.: Temporal variation of SOC enrichment from interrill erosion over prolonged rainfall simulations, Agriculture, 3, 726-740, 2013a. 
Hu, Y., Fister, W., Rüegg, H. R., Kinnell, P. I. A., and Kuhn, N. J.: The use of Equivalent Quatz Size and settling tube apparatus to fractionate soil aggregates by settling velocity, Geomorphol. Tech. Online Ed. Br. Soc. Geomorphol., Section 1.1.1, $2013 \mathrm{~b}$.

Iserloh, T., Fister, W., Seeger, M., Willger, H., and Ries, J. B.: A small portable rainfall simulator for reproducible experiments on soil erosion, Soil Tillage Res., 124, 131-137, 2012.

Kaiser, M., Berhe, A. A., Sommer, M., and Kleber, M.: Application of ultrasound to disperse soil aggregates of high mechanical stability, J. Plant. Nutr. Soil. Sci., 175, 521-526, 2012.

Kinnell, P. I. A.: Particle travel distances and bed and sediment compositions associated with rain-Impacted flows, Earth. Surf. Proc. Land., 26, 749-758, 2001.

Kinnell, P. I. A.: Raindrop-impact-induced erosion processes and prediction: a review, Hydrol. Proc., 19, 2815-2844, 2005.

Kuhn, N. J.: Assessing lateral organic Carbon movement in small agricultural catchments, in: Mattertal - ein Tal in Bewegung, edited by: Graf, C., Publikation zur Jahrestagung der Schweizerischen Geomorphologischen Gesellschaft 29 Juni-1 Juli 2011, St. Niklaus. Birmensdorf, Eidg. Forschungsanstalt WSL, 151$164,2013$.

Kuhn, N. J. and Armstrong, E. K.: Erosion of organic matter from sandy soils: solving the mass balance, Catena, 98, 87-95, 2012.

Kuhn, N. J., Hoffmann, T., Schwanghart, W., and Dotterweich, M.: Agricultural soil erosion and global carbon cycle: controversy over?, Earth. Surf. Proc. Land., 34, 1033-1038, 2009.

Lal, R.: Soil carbon sequestration impacts on global climate change and food security, Science, 304, 1623-1627, 2004.

Lal, R.: Soil erosion and carbon dynamics, Soil Till. Res., 81, 137142, 2005.

Le Bissonnais, Y.: Aggregate stability and assessment of soil crustability and erodibility: I. Theory and methodology, Eur. J. Soil Sci., 47, 425-437, 1996.

Legout, C., Leguedois, S., and Le Bissonnais, Y.: Aggregate breakdown dynamics under rainfall compared with aggregate stability measurements, Eur. J. Soil Sci., 56, 225-237, 2005.

Loch, R. J.: Settling velocity - a new approach to assessing soil and sediment properties, Comput. Electron. Agr., 31, 305-316, 2001.

Lu, H., Moran, C. J., and Prosser, I. P.: Modelling sediment delivery ratio over the Murray Darling Basin, Environ. Model. Softw., 21, 1297-1308, 2006.
MeteoSwiss: Monthly total precipitation during April, May, and June at Station Arisdorf near Möhlin from 1985 to 2012, 2013.

Nadeu, E., De Vente, J., Martínez-Mena, M., and Boix-Fayos, C.: Exploring particle size distribution and organic carbon pools mobilized by different erosion processes at the catchment scale, J. Soil. Sediment., 11, 667-678, 2011.

Olsen, P. and Kristensen, P. R.: Using a GIS system in mapping risks of nitrate leaching and erosion on the basis of SOIL/SOIL-N and USLE simulations, Nutr. Cycl. Agroecosys., 50, 307-311, 1998.

Pieri, L., Bittelli, M., Wu, J. Q., Dun, S., Flanagan, D. C., Pisa, P. R., Ventura, F., and Salvatorelli, F.: Using the Water Erosion Prediction Project (WEPP) model to simulate field-observed runoff and erosion in the Apennines Mountain Range, Italy. J. Hydrol., 336, 84-97, 2007.

Quinton, J. N., Catt, J. A., and Hess, T. M.: The selective removal of phosphorus from soil: is event size important?, J. Environ. Qual., 30, 538-545, 2001.

Stallard, R. F.: Terrestrial sedimentation and the carbon cycling: coupling weathering and erosion to carbon burial, Global Biogeochem. Cy., 12, 231-257, 1998.

Starr, G. C., Lal, R., Malone, R., Hothem, D., Owens, L., and Kimble, J.: Modeling soil carbon transported by water erosion process, Land Degrad. Dev., 11, 83-91, 2000.

Stokes, G. G.: On the effect of the internal friction of fluids on the motion of pendulums, Trans. Camb. Phil. Soc., 9, 8-106, 1851.

Torri ,D., Regüés, D., Pellegrini, S., and Bazzoffi, P.: Within-storm soil surface dynamics and erosive effects of rainstorms, Catena, 38, 131-150, 1999.

van Oost, K., Beuselinck, L., Hairsine, P. B., and Govers, G.: Spatial evaluation of a multi-class sediment transport and deposition model, Earth. Surf. Proc. Land., 29, 1027-1044, 2004.

van Oost, K., Quine, T. A., Govers, G., De Gryze, S., Six, J., Harden, J. W., Ritchie, J. C., McCarty, G. W., Heckrath, G., Kosmas, C., Giraldez, J. V., Marques da Silva, J. R., and Merckx, R.: The impact of agricultural soil erosion on the global carbon cycle, Science, 318, 626-629, 2007.

Walling, D. E.: Erosion and sediment yield research - some recent perspectives, J. Hydrol., 100, 113-141, 1988.

Wang, J. G., Li, Z. X., Cai, C. F., and Ma R. M.: Particle size and shape variation of Ultisol aggregates affected by abrasion under different transport distances in overland flow, Catena, 123, 153$162,2014$. 